ljtihad: Jurnal Wacana Hukum Islam dan Kemanusiaan

Vol. 18, No. 2 (2018), pp. 175-192, doi : 10.18326/ijtihad.v18i2.175-192

\title{
Analisis hukum Islam terhadap pengembangan wakaf berbasis sukuk untuk pemberdayaan tanah yang tidak produktif di Indonesia
}

\author{
Siska Lis Sulistiani, Eva Misfah Bayuni dan Muhammad Yunus \\ Universitas Islam Bandung \\ E-mail: ummufathir26@gmail.com, evambayuni@gmail.com,yunus_rambe@yahoo.co.id \\ DOI : 10.18326/ijtihad.v18i2.175-192
}

Waqf has more flexibility than zakat so that the form of waqf will continue to grow in accordance with the times. The development of the waqf must still be in the corridor of the Shari'a so that the value of ubudiyah and iqtishadiyah remain. The potential of waqf land in Indonesia is so large, making the number of unproductive waqf land due to limited aspects of funding and management. Sukuk-based waqf innovation launched in early 2017 by the Government in order to maximize the potential of waqf land in Indonesia, only the legal aspects of sukuk itself are legally still legitimate. The methodology used is qualitative research methods through literature study, with normative juridical research types and secondary data sources collected by documentary and interview methods and analyzed descriptively qualitatively so that the level of synchronization and feasibility of norms is known. The results of this study are that waqf and sukuk stand from 2 different contract goals, namely tabarru and tijaroh contracts, which are combined in order to bring greater value to benefit. The position of the sukuk-based waqf law if it is built on the contract of sukuk ijarah which is almost similar to bai al-wafa according to the jumhur ulama is prohibited, except for Hanafi schools that allow it. This is in line with the DSN fatwa regarding sukuk and Article 112-113 of the KHES regarding Bai al-Wafa. Apart from differences of opinion in the context of fiqh, it is necessary to pay attention to the clear regulatory aspects that underlie sukuk-based waqf, pay attention to the administration of waqf assets both land and building certificates and waqf certificates and attention to sharia legality aspects so that the main purpose of waqf for the benefit of the people can still achieved without reducing the value or the form of waqf assets

Wakaf memiliki fleksibilitas yang lebih dibandingkan zakat sehingga bentuk wakaf akan terus berkembang sesuai dengan perkembangan zaman. Perkembangan wakaf tersebut tetap harus dalam 
koridor syariat sehingga nilai ubudiyah dan iqtishadiyah nya tetap ada. Potensi tanah wakaf di Indonesia yang begitu besar, menjadikan banyaknya tanah wakaf yang tidak produktif diakibatkan terbatasnya aspek pendanaan dan manajemen. Inovasi wakaf berbasis sukuk yang diluncurkan di awal 2017 oleh Pemerintah dalam rangka memaximalkan potensi tanah wakaf di Indonesia, hanya saja aspek hukum sukuk itu sendiri secara hukum masih khilafiah. Metodologi yang digunakan adalah metode penelitian kualitatif melalui studi kepustakaan, dengan jenis penelitian yuridis normatif dan sumber data sekunder yang dikumpulkan dengan metode dokumenter dan wawancara lalu dianalisis secara deskriptif kualitatif sehingga diketahui taraf sikronisasi dan kelayakan norma. Hasil penelitian ini bahwa wakaf dan sukuk berdiri dari 2 tujuan akad yang berbeda yaitu akad tabarru dan tijaroh, yang digabungkan dalam rangka menghadirkan nilai maslahat yang lebih besar. Kedudukan hukum wakaf berbasis sukuk ini jika dibangun diatas akad sukuk ijarah yang hampir serupa bai al-wafa menurut jumhur ulama diharamkan, kecuali madzhab hanafi yang membolehkannya. Hal ini yang selaras dengan fatwa DSN tentang sukuk dan Pasal 112-113 KHES tentang bai al-wafa. Terlepas dari perbedaan pendapat dalam konteks fiqh ini, perlu diperhatikan aspek regulasi yang jelas yang melandasi wakaf berbasis sukuk ini, memperhatikan perapihan administrasi aset wakaf baik sertifikat tanah dan bangunan maupun sertifikat wakaf dan perlu diperhatikan aspek legalitas syariah agar tujuan utama wakaf untuk kemaslahatan umat tetap dapat tercapai tanpa mengurasi nilai ataupun wujud dari asset wakaf.

Keywords: waqf; sukuk; productive, Islamic law

\section{Pendahuluan}

Wakaf merupakan bentuk nilai kebaikan Islam yang mengajarkan untuk mengembangkan harta secara amanah dan multimanfaat. Wakaf memiliki fleksibilitas lebih tinggi dibandingkan dengan zakat sehingga para ulama dan cendikiawan muslim memiliki peluang berijtihad dalam mengembangkan bentuk wakaf sesuai kebutuhan zamannya.

Akan tetapi, lembaga wakaf selama ini dianggap sebagai lembaga nirlaba yang tidak berkonsentrasi pada profit oriented, dan hanya fokus pada masalah ibadah sehingga pengembangannya hanya berhenti pada pembangunan tempat ibadah saja. Wakaf memainkan peran ekonomi dan sosial yang sangat penting dalam sejarah Islam, wakaf berfungsi sebagai sumber pembiayaan bagi masjid-masjid, sekolah-sekolah, pengkajian dan penelitian, rumahrumah sakit, pelayanan sosial dan pertahanan (Anwar, 2007; 75). Indonesia memiliki aset tanah wakaf yang sangat besar, sebagaimana data berikut: 
Analisis hukum Islam terhadap pengembangan wakaf berbasis sukuk...(Siska Lis Sulistiani, dkk.)

Tabel 1.

Data Tanah Wakaf Seluruh Indonesia (BWI, 2016)

\begin{tabular}{|c|c|c|c|c|c|}
\hline \multirow{2}{*}{ No } & \multirow{2}{*}{ Provinsi } & \multirow{2}{*}{ Jumlah } & \multicolumn{2}{|c|}{ Sertifikat Wakaf } & \multirow{2}{*}{ Luas Total (M2) } \\
\hline & & & Sudah & Belum & \\
\hline 1 & $\begin{array}{l}\text { Nanggroe Aceh } \\
\text { Darussalam }\end{array}$ & 24.898 & 13.730 & 11.168 & $767.869 .011,58$ \\
\hline 2 & Sumatera Utara & 16.280 & 7.761 & 8.519 & $36.035 .460,00$ \\
\hline 3 & Sumatera Barat & 6.643 & 4.420 & 2.223 & $212.212 .380,00$ \\
\hline 4 & Sumatera Selatan & 6.394 & 3.521 & 2.873 & $380.456 .227,29$ \\
\hline 5 & Riau & 8.152 & 2.641 & 5.691 & $1.183 .976 .528,00$ \\
\hline 6 & Jambi & 5.918 & 3.785 & 2.133 & $13.516 .703,00$ \\
\hline 7 & Bengkulu & 2.759 & 1.869 & 890 & $7.122 .171,22$ \\
\hline 8 & Lampung & 14.591 & 8.372 & 6.219 & $22.990 .814,00$ \\
\hline 9 & Bangka Belitung & 1.133 & 779 & 354 & $3.243 .060,00$ \\
\hline 10 & Kepulauan Riau & 1.187 & 326 & 861 & $1.066 .799,00$ \\
\hline 11 & DKI Jakarta & 7.422 & 4.623 & 2.799 & $3.013 .640,00$ \\
\hline 12 & D.I. Yogyakarta & 8.547 & 8.051 & 496 & $2.933 .943,00$ \\
\hline 13 & Jawa Barat & 74.860 & 45.873 & 28.987 & $116.662 .017,81$ \\
\hline 14 & Jawa Tengah & 103.294 & 82.641 & 20.653 & $163.169 .706,97$ \\
\hline 15 & Jawa Timur & 74.429 & 54.193 & 20.236 & $58.239 .272,20$ \\
\hline 16 & Banten & 20.089 & 11.049 & 9.040 & $39.322 .270,00$ \\
\hline 17 & Bali & 1.399 & 1.132 & 267 & $13.990 .000,00$ \\
\hline 18 & Kalimantan Barat & 4.467 & 2.257 & 2.210 & $27.544 .360,00$ \\
\hline 19 & Kalimantan Tengah & 2.642 & 1.631 & 1.011 & $5.778 .500,00$ \\
\hline 20 & Kalimantan Selatan & 9.265 & 7.582 & 1.683 & $58.239 .272,20$ \\
\hline 21 & Kalimantan Timur & 3.423 & 772 & 2.651 & $13.984 .104,00$ \\
\hline 22 & Sulawesi Utara & 887 & 420 & 467 & $1.905 .272,70$ \\
\hline 23 & Sulawesi Tenggara & 2.386 & 1.516 & 870 & $5.225 .958,00$ \\
\hline 24 & Sulawesi Tengah & 3.173 & 2.051 & 1.122 & $165.042 .816,23$ \\
\hline 25 & Sulawesi Selatan & 10.440 & 5.486 & 4.954 & $1.029 .030 .278,00$ \\
\hline 26 & Sulawesi Barat & 2.448 & 571 & 1.877 & $3.251 .700,00$ \\
\hline 27 & Papua & 346 & 142 & 204 & $694.466,00$ \\
\hline 28 & Papua Barat & 338 & 105 & 233 & $591.117,00$ \\
\hline 29 & Nusa Tenggara Timur & 1.272 & 1.047 & 225 & $5.311 .787,00$ \\
\hline 30 & Nusa Tenggara Barat & 12.105 & 7.031 & 5.074 & $25.816 .325,00$ \\
\hline 31 & Maluku & 1.215 & 449 & 766 & $5.006 .359,00$ \\
\hline 32 & Maluku Utara & 1.489 & 605 & 543 & $30.223 .191,00$ \\
\hline \multirow[t]{2}{*}{33} & Gorontalo & 1.877 & 729 & 1.148 & $1.663 .350,00$ \\
\hline & Jumlah & 435.768 & 287.160 & 148.447 & $4.359 .443 .170,00$ \\
\hline
\end{tabular}

Di tahun 2012 potensi tanah wakaf di Indonesia mencapai 3,4 miliar meter persegi yang tersebar di 420.003 lokasi seluruh Indonesia ( Bimas Islam, 2012), dan di 2015 menurut Kepala Divisi Pengelolaan dan Pemberdayaan Wakaf Robbiyantono (antaranews.com, 2015) menjelaskan bahwa dari data yang dihimpun diketahui tanah wakaf di Indonesia tercatat seluas 4,2 miliar meter persegi di 42.3000 lokasi, serta dari data di atas pada tahun 2016 luas tanah meningkat menjadi 4,36 miliar meter persegi dalam waktu 4 tahun terus terjadi kenaikan jumlah tanah wakaf yang signifikan. Tanah wakaf yang sangat luas ini merupakan aset potensial yang menjanjikan keuntungan yang sangat besar apabila dikembangkan secara 
ljtihad: Jurnal Wacana Hukum Islam dan Kemanusiaan, Volume 18, No. 2, Desember 2018: 175-192

produktif. Keuntungan dari hasil wakaf tanah tersebut dapat digunakan untuk program kesejahteraan masyarakat, misalnya pengentasan kemiskinan, bantuan pendidikan, bantuan kesehatan, penyediaan rumah murah bagi rakyat yang tidak mampu.

Di era globalisasi ini dengan tantangan ekonomi yang terus menuntut persaingan, melahirkan dampak tingginya angka kemiskinan. Di Indonesia Badan Pusat Statistik (BPS) mencatat jumlah penduduk miskin Indonesia per maret 2017 mencapai 27,77 juta orang, bertambah 6,90 ribu orang dibandingkan dengan September 2016 sebanyak 27,76 juta orang (tempo.co, 2017). Islam sebagai agama yang rahmatan lil'alamin sehingga tidak hanya mengatur aspek ibadah ritual saja, namun membahas mengenai konsep nilai ibadah yang sekaligus memiliki nilai ekonomi yang dapat memberi manfaat kepada sebanyak-banyaknya manusia.

Tanah wakaf yang begitu banyak di Indonesia secara kuantitas, tapi belum maximal secara kwalitas pemberdayaannya. Mengingat, masih banyaknya tanah wakaf yang terbengkalai karena kurangnya dana serta pembinaan kepada para pengelolanya. Hal tersebut menyebabkan banyaknya tanah wakaf yang tidak produktif dan bahkan dibiarkan saja. Dari banyaknya masalah tanah wakaf yang tidak produktif, pada awal 2017 Bank Indonesia bekerjasama dengan Kementerian BUMN, Kementerian Keuangan, Badan Wakaf Indonesia (BWI), dan perwakilan BUMN meluncurkan model sukuk linked waqaf yang merupakan inovasi untuk mengoptimalkan pemanfaatan aset wakaf dengan sukuk (Anik, 2017).

Gambar.1. Perkembangan Sukuk di Indonesia(OJK, 2017)

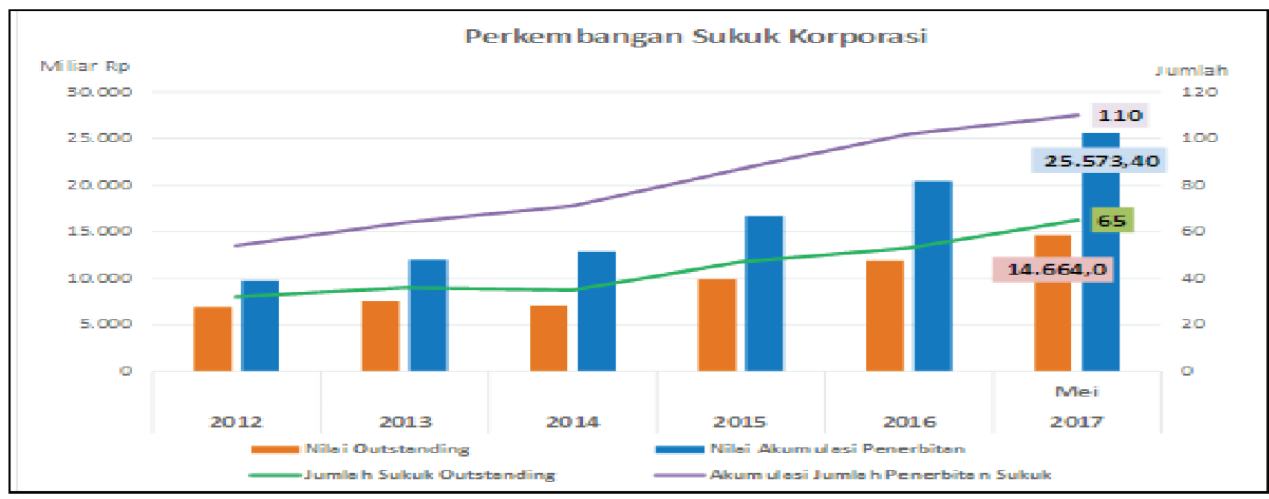

Gambar 1. Perkembangan Sukuk di Indonesia Sumber: Otoritas Jasa Keuangan, (2017) 
Respati (2016), melalui project based sukuk (PBS), pemerintah memperoleh alternatif sumber pembiayaan khusus untuk membiayai proyek infrastruktur. Sejak diterbitkan pertama kali pada 2012 total penerbitan PBS telah mencapai Rp 81,17 triliun, dari total penerbitan sukuk negara yang sebesar Rp 380,21 triliun. Jenis proyek yang dapat dibiayai oleh sukuk negara mencakup proyek pembangunan infrastruktur (sektor energi, telekomunikasi, perhubungan, pertanian, industri manufaktur dan perumahan rakyat), penyediaan pelayanan umum, pemberdayaan industri dalam negeri, dan pembangunan lain sesuai dengan kebijakan strategis pemerintah. Selanjutnya, Dewan Syariah Nasional Majelis Ulama Indonesia (DSN-MUI), juga telah mengeluarkan sebuah keputusan terkait kriteria proyek yang sesuai dengan prinsip syariah, sehingga bisa dibiayai oleh sukuk negara. Keputusan tersebut tertuang dalam Ketetapan DSN MUI Nomor 01/DSN-MUI/III/2012 tentang Kriteria Proyek Sesuai dengan Prinsip Syariah. Ketetapan DSN MUI tersebut menyatakan bahwa proyek bisa digunakan sebagai dasar penerbitan dan/atau dibiayai melalui penerbitan Surat Berharga Syariah Negara sepanjang tidak bertentangan dengan prinsip syariah dan peraturan perundang-undangan yang berlaku. Proyek tersebut pun harus memenuhi sejumlah kriteria persyaratan.

Pada awalnya sukuk ini telah dimulai dari negara muslim lain salah satunya Bahrain yang pada tahun 1999 memfatwakan bolehnya negara menerbitkan sukuk ijarah untuk membiayai belanja negara. Dengan diterbitkannya sukuk ijarah tersebut Bahrain dapat mengumpulkan dana sebanyak 10 Milyar US Dolar (Erwandi, 2016). Akan tetapi, secara spesifik wakaf berbasis sukuk ini belum ada fatwa DSN MUI yang membahasnya, baru ada Fatwa DSN MUI terkait Sukuk No.71/DSN-MUI/VI/2008 tentang sale and lease back saja. Akan tetapi status hukumnya pun masih menjadi sorotan dalam hukum Islam karena akad sukuk menurut Hamid Mirah $(2008$, 402) merupakan bagian dari Jual beli Inah dan dalam Mausu'ab Fighiyah Kuwaytijyah akad sukuk yang berkembang serupa dengan jua beli wafa' yang diharamkan jumhur ulama (Erwandi, 2016). Oleh karena itu, tujuan utama dalam memberdayakan tanah wakaf pun harus sejalan dengan bentuk pembiayaan yang berlandaskan syari'ah, mengingat sukuk dengan mekanisme bay'il wafa diharamkan para jumhur ulama.

Dari pemanfaatan akad sukuk yang berkembang di Indonesia ini dalam rangka memberdayakan banyaknya tanah wakaf yang tidak produktif, maka para ekonom muslim mencoba mengintegrasikan konsep wakaf yang memiliki banyak nilai sosial ekonomi ini 
dengan konsep sukuk yang hari ini masih menuai perbedaan pendapat dikalangan ulama. Mengingat konsep wakaf itu harus berkembang dengan produktif, namun harus dengan konsep akad yang tidak diharamkan dalam Islam sehingga dapat tercapai tujuan kebaikan yang berlandaskan syari'ah.

Dari latar belakang di atas, maka peneliti akan membahas penelitian dengan judul "Analisis Pengembangan Wakaf Berbasis Sukuk untuk Pemberdayaan Tanah yang tidak Produktif di Indonesia menurut Hukum Islam"

\section{Metode penelitian}

Pendekatan penelitian ini adalah penelitian kualitatif, melalui pendekatan penelitian hukum yuridis normatif yang mencakup penelitian terhadap asas-asas hukum, sistematika hukum, taraf sinkronisasi hukum, sejarah hukum dan perbandingan hukum(Soekanto, 2011, 20). Penelitian hukum yuridis normatif ini, data yang diperlukan berupa data sekunder atau data kepustakaan dan dokumen hukum yang berupa bahan-bahan hukum. Yang dipergunakan dalam penelitian ini adalah studi kepustakaan (library research) yaitu jenis penelitian yang data-datanya diperoleh dari buku, kitab, majalah, surat kabar, jurnal dan catatan lainnya yang memiliki relevansi dengan permasalahan yang akan dibahas.

Tehnik pengumpulan data menggunakan Studi kepustakaan (library research) yaitu jenis penelitian yang data-datanya diperoleh dari buku, kitab, majalah, surat kabar, jurnal dan catatan lainnya yang memiliki relevansi dengan permasalahan yang akan dibahas. Pada penelitian hukum normatif ini, pengolahan data hanya ditujukan pada analisis data secara deskriptif kualitatif, di mana materi atau bahan-bahan hukum tersebut untuk selanjutnya akan dipelajari dan dianalisis muatannya, sehingga dapat diketahui taraf sikronisasinya, kelayakan norma, dan pengajuan gagasan-gagasan normatif baru, khususnya dalam hukum Islam dengan menggunakan kaidah-kaidah fiqhiyah dan teori hukum terkait permasalahan ini. Kualitatif dimaksudkan yaitu analisis yang bertitik tolak pada usaha penemuan asas dari informasi yang bersifat monografis dan responden, memahami kebenaran yang diperoleh dari hasil pengamatan dan pertanyaan kepada sejumlah sumber baik secara lisan maupun tertulis selama dalam melakukan kegiatan penelitian, diantara analisis data hukum melalui penafsiran, analogi dan argumentum. 


\section{Gambar 2}

\section{Metodologi Penelitian}
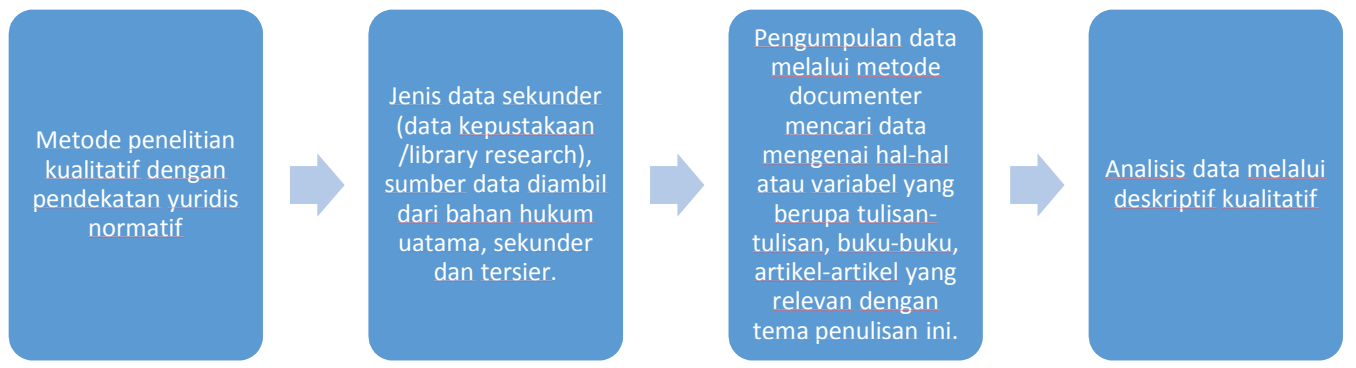

\section{Penelitian terdahulu dan kerangka teori}

Melirik wakaf berarti mencari celah untuk memberdayakan aset ekonomi masyarakat. Hal ini disebabkan oleh ketersediaan sarana ekonomi yang terdapat dalam wakaf itu sendiri. Apa yang dimaksud dengan ekonomi disini adalah sisi-sisi finansial material sebagai kebutuhan dasar yang bisa diperoleh melalui pengelolaan dan pengembangan harta wakaf. Berdasarkan asumsi ini, harta wakaf memang harus dikelola secara produktif agar menghasilkan peluang-peluang bagi terbukanya sektor-sektor strategis yang menguntungkan, seperti membuka lapangan kerja baru, pengelolaan pelayanan publik yang meringankan beban ekonomi masyarakat, dan memberikan fasilitas bagi pengembangan usaha ekonomi kecil dan menengah (Kemenag, 2008: 14).

Pemberdayaan tanah wakaf menjadi wakaf yang produktif dimulai dengan pembiayaan tanah wakaf tersebut. Banyaknya tanah wakaf yang tidak dapat diberdayakan secara produktif diakibatkan oleh ketiadaan dana untuk memberdayakan atau mengelola tanah wakaf tersebut. Pembiayaan menjadi faktor penting dalam pemberdayaan tanah wakaf agar menjadi wakaf yang produktif. Pembiayaan merupakan muqaddimatul wājib dari pengelolaan atau investasi tanah wakaf, dengan kata lain proses investasi tanah wakaf tanah wakaf menuntut adanya usaha pembiayaan terlebih dahulu atas harta wakaf tersebut. Menurut Monzer Kahf, para ulama terdahulu telah memikirkan model- model pembiayaan wakaf tanah. Hal ini menunjukkan bahwa pembiayaan merupakan hal penting yang harus dipikirkan nazhir sebelum melakukan pengelolaan dan pengembangan aset wakaf (Qahaf, 2006: 242). Penelitian terdahulu terkait dengan penelitian penulis disajikan dalam tabel berikut : 
Tabel 2.

Penelitian Terdahulu

\begin{tabular}{|c|c|c|c|c|c|}
\hline No & Peneliti & $\begin{array}{l}\text { Judul penelitian } \\
\text { dan tahun }\end{array}$ & $\begin{array}{c}\text { Hasil } \\
\text { Penelitian }\end{array}$ & Persamaan & Perbedaan \\
\hline 1 & $\begin{array}{l}\text { Ahmad } \\
\text { Furqon, Jurnal } \\
\text { Economica } \\
\text { Vol.V Edisi } 1 \\
\text { Mei } 2014 .\end{array}$ & $\begin{array}{l}\text { Model-Model } \\
\text { Pembiayaan Wakaf } \\
\text { Tanah Produktif }\end{array}$ & $\begin{array}{l}\text { Makalah ini } \\
\text { menemukan } \\
\text { banyak model } \\
\text { pembiayaan yang } \\
\text { dapat diterapkan } \\
\text { bagi pembiayaan } \\
\text { tanah wakaf, } \\
\text { akan tetapi } \\
\text { pembiayaan } \\
\text { yang mengurangi } \\
\text { resiko kerugian } \\
\text { perlu menjadi } \\
\text { pertimbangan } \\
\text { lembaga } \\
\text { wakaf dalam } \\
\text { memilih model } \\
\text { pembiayaan } \\
\text { tersebut. }\end{array}$ & $\begin{array}{l}\text { Sama-sama } \\
\text { membahas } \\
\text { tentang } \\
\text { waskaf tanah }\end{array}$ & $\begin{array}{l}\text { Makalah ini hanya } \\
\text { membahas secara } \\
\text { umum model } \\
\text { pembiayaan wakaf } \\
\text { tanah, dan tidak } \\
\text { membahas spesifik } \\
\text { hukum Islam dari } \\
\text { segi akad dan } \\
\text { obyeknya. }\end{array}$ \\
\hline 2 & $\begin{array}{l}\text { M.Imam } \\
\text { Syairozi, } \\
\text { Septyan Budy } \\
\text { Cahya, Jurnal } \\
\text { Penelitian Ilmu } \\
\text { Manajemen } \\
\text { Univ. Islam } \\
\text { Lamongan Vol. } \\
\text { II No.2 Juni } \\
\text { 2016, ISSN } \\
\text { 2502-3780 }\end{array}$ & $\begin{array}{l}\text { Sukuk Al-Intifaa: } \\
\text { Integrasi Sukuk } \\
\text { dan Wakaf dalam } \\
\text { meningkatkan } \\
\text { produktifias Sektor } \\
\text { Wakaf Pendorong } \\
\text { Investasi Pada } \\
\text { Pasar Modal } \\
\text { Syariah }\end{array}$ & \begin{tabular}{|l|} 
Dual integrasi \\
antara sukuk dan \\
wakaf dalam \\
Sukuk Al Intifa‘a \\
diharapkan \\
mampu \\
menciptakan \\
sebuah \\
instrumen \\
keuangan \\
yang bisa \\
memaksimalkan \\
produktofitas \\
sektor pasar \\
modal syariah \\
dan sektor wakaf.
\end{tabular} & $\begin{array}{l}\text { Sama-sama } \\
\text { menulis } \\
\text { tentang sukuk } \\
\text { dan wakaf. }\end{array}$ & $\begin{array}{l}\text { Makalah ini } \\
\text { lebih fokus pada } \\
\text { konsep umum } \\
\text { memaksimalkan } \\
\text { produktifitas } \\
\text { sektor pasar modal } \\
\text { syariah tidak } \\
\text { membahas tentang } \\
\text { analisis khusus } \\
\text { hukum islam } \\
\text { tentang kedudukan } \\
\text { wakaf berbasis } \\
\text { sukuk. }\end{array}$ \\
\hline
\end{tabular}




\begin{tabular}{|c|c|c|c|c|c|}
\hline No & Peneliti & $\begin{array}{l}\text { Judul penelitian } \\
\text { dan tahun }\end{array}$ & $\begin{array}{c}\text { Hasil } \\
\text { Penelitian }\end{array}$ & Persamaan & Perbedaan \\
\hline 3 & $\begin{array}{l}\text { Lastuti Abu } \\
\text { Bakar dan Tri } \\
\text { Handayani, } \\
\text { Jurnal } \\
\text { Jurisprudence } \\
\text { Vol.7 N0.1 Juni } \\
2017\end{array}$ & $\begin{array}{l}\text { Kesiapan } \\
\text { Infrastruktur } \\
\text { Hukum Dalam } \\
\text { Penerbitan Sukuk } \\
\text { (Surat Berharga } \\
\text { Syariah) Sebagai } \\
\text { Instrumen } \\
\text { Pembiayaan Dan } \\
\text { Investasi Untuk } \\
\text { Mendorong } \\
\text { Pertumbuhan } \\
\text { Pasar Modal } \\
\text { Syariah Indonesia }\end{array}$ & $\begin{array}{l}\text { Regulasi sukuk di } \\
\text { Indonesia masih } \\
\text { bersifat parsial } \\
\text { dan tersebar } \\
\text { dalam berbagai } \\
\text { aturan, sehingga } \\
\text { mengakibatkan } \\
\text { rendahnya } \\
\text { pemahaman } \\
\text { pelaku usaha dan } \\
\text { investor terhadap } \\
\text { kerangka } \\
\text { hukum sukuk, } \\
\text { serta jaminan } \\
\text { kepastian } \\
\text { hukum. }\end{array}$ & $\begin{array}{l}\text { Sama-sama } \\
\text { membahas } \\
\text { aspek hukum } \\
\text { sukuk. }\end{array}$ & $\begin{array}{l}\text { Makalah ini hanya } \\
\text { membahas aspek } \\
\text { hukum positif dari } \\
\text { sukuk, tapi tidak } \\
\text { membahas tentang } \\
\text { wakaf berbasis } \\
\text { sukuk dan tidak } \\
\text { menganalisisnya } \\
\text { dalam hukum } \\
\text { islam. }\end{array}$ \\
\hline 4 & $\begin{array}{l}\text { Anik, Iin } \\
\text { Emy Prastiwi. } \\
\text { Jurnal Ilmiah } \\
\text { Ekonomi Islam } \\
\text { Surakarta, Vol.3 } \\
\text { No.3 2017. }\end{array}$ & $\begin{array}{l}\text { Perkembangan } \\
\text { Instrumen Sukuk } \\
\text { dalam Mendukung } \\
\text { Pembangunan } \\
\text { Infrasuktur }\end{array}$ & $\begin{array}{l}\text { Pentingnya } \\
\text { perkembangan } \\
\text { Instrumen } \\
\text { Sukuk dalam } \\
\text { Mendukung } \\
\text { Pembangunan } \\
\text { Infrasuktur diI } \\
\text { Indonesia }\end{array}$ & $\begin{array}{l}\text { Sama-sama } \\
\text { membahas } \\
\text { terkait sukuk }\end{array}$ & $\begin{array}{l}\text { Makalah ini hanya } \\
\text { membahas aspek } \\
\text { ekonomi sukuk } \\
\text { tidak membahas } \\
\text { aspek hukum } \\
\text { Islam. }\end{array}$ \\
\hline
\end{tabular}

Mekanisme wakaf berbasis sukuk dalam pemberdayaan tanah tidak produktif di Indonesia

Saat ini, model-model pembiayaan bertambah banyak, seiring dengan kemunculan lembaga keuangan Islam, sehingga memungkinkan nazhir untuk mengadakan kerjasama dengan lembaga keuangan Islam dalam pembiayaan tanah wakaf, atau dengan menggalang dana dari masyarakat atau publik, dengan model wakaf uang, wakaf saham atau wakaf amal kolektif, maupun wakaf sukuk. Sehingga dengan adanya wakaf sukuk ini sebagai bagian dari bentuk pembiayaan terhadap banyaknya tanah wakaf yang belum produktif karena terhalang salah satunya karena aspek pendanaan maupun administratif.

Walaupun belum secara resmi diputuskan bentuk yang ditawarkan dalam pembiayaan asset wakaf melalui sukuk ini, akan tetapi tawaran tersebut disampaikan oleh pihak Kementrian 
ljtihad: Jurnal Wacana Hukum Islam dan Kemanusiaan, Volume 18, No. 2, Desember 2018: 175-192

keuangan (Gatra, 2018) Kementerian Keuangan mencatat pada 2015, jumlah tanah wakaf atau tanah yang disumbangkan untuk tujuan sosial di Indonesia mencapai 5 milyar meter persegi yang tersebar di 400.000 titik di seluruh Indonesia dengan nilai setara Rp 2.050 trilyun. Dengan nilai yang besar tersebut, melalui instrumen sukuk atau surat utang syariah, pengelola pesantren dapat melakukan perjanjian atau akad dengan BUMN diawasi oleh pengelola tanah wakaf atau nazir untuk melakukan pembangunan unit bisnis yang lebih bernilai bisnis seperti Rumah Sakit. Setelah akad disepakati dan dana didapatkan melalui sukuk, maka pembangunan rumah sakit di atas tanah wakaf bisa dilakukan. Keuntungan operasional rumah sakitlah yang nantinya digunakan untuk membayar sukuk dengan skema bagi hasil antar kedua belah pihak.

\section{Gambar 3}

Ilustrasi alur wakaf linked wakaf (sumber: diolah, 2018)

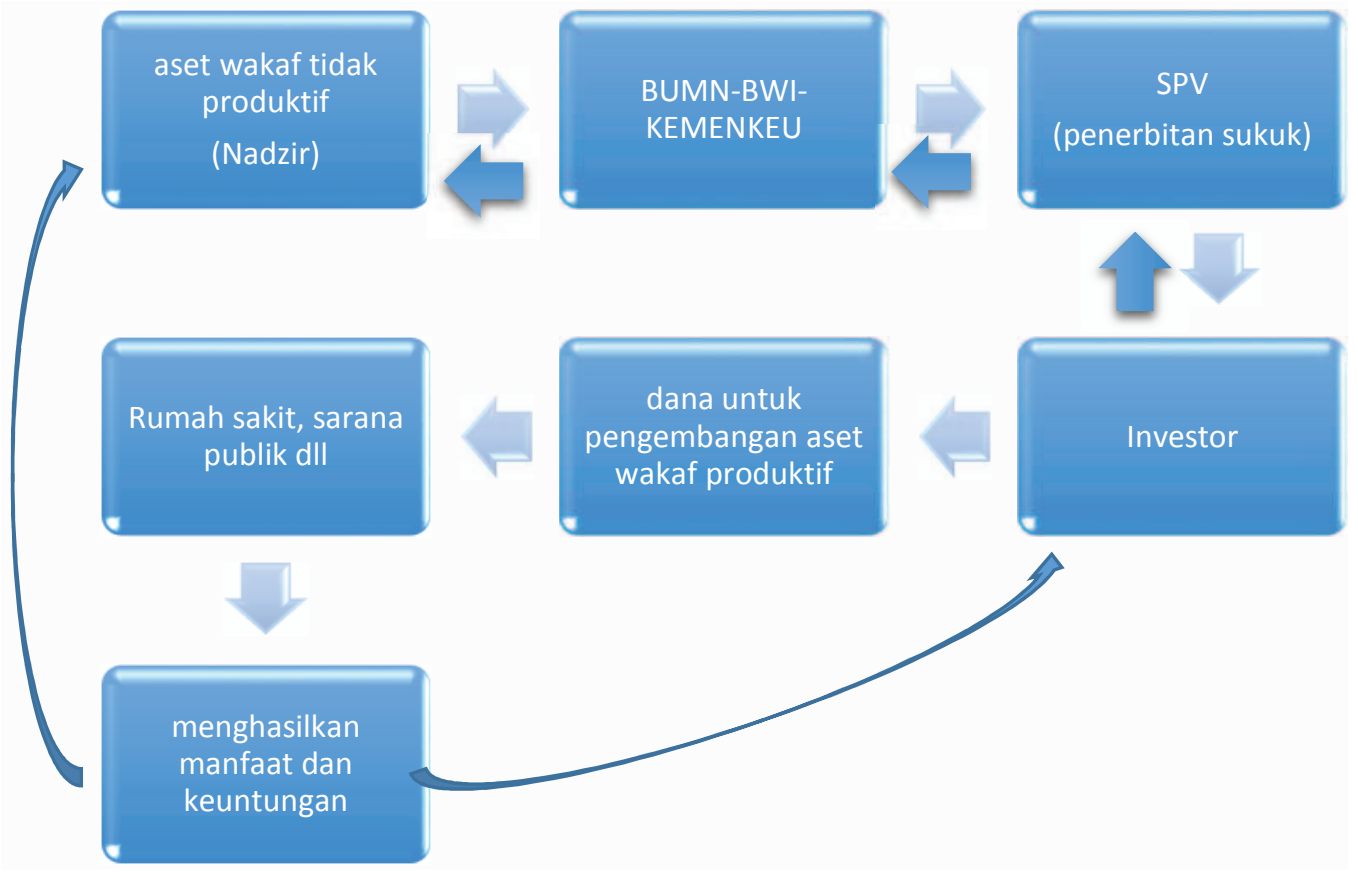


Menurut Yudha (2017), Kabar terbaru adalah penerbitan sukuk wakaf oleh pemerintah. Model sukuk wakaf diluncurkan oleh Bank Indonesia bekerjasama dengan Kementerian BUMN, Kementerian Keuangan, Badan Wakaf Indonesia (BWI), dan perwakilan BUMN meluncurkan model sukuk linked waqaf yang merupakan inovasi untuk mengoptimalkan pemanfaatan aset Wakaf dengan Sukuk. Yasinta (2016), yang memungkinkan potensi penerbitan sukuk wakaf adalah BUMN karena BUMN juga bergerak dibidang pembangunan infrastruktur. Respati (2016), BUMN yang menerbitkan sukuk dan menawarkannya ke investor, setelah masuk dana dari penjualan sukuk lalu dana akan digunakan untuk membangun infrastruktur bersama dengan kontraktor. Ketika aset jadi, maka akan disewakan. Hasilnya kemudian akan dibagi ke nadzhir maupun pemilik sukuk. Di akhir periode aset akan dikembalikan ke nadzhir.

Dari beberapa uraian tersebut mengindikasikan belum adanya akad yang resmi yang akan digunakan dalam pengembangan akad dalam upaya pengembangan wakaf di Indonesia. Berdasarkan deskripsi fatwa AAOIFI dari segi obyek akad, terdapat tiga jenis sukuk ijarah. Pertama, sukuk ijarah Milkiyah al-A'yan al-Mu'jarah atau certificates of ownership in leased assets. Sukuk ijarah Milkiyah al-A'yan al-Mu'jarah yaitu sukuk ijarah yang melambangkan kepemilikan atas aset yang bertujuan untuk disewakan (investor adalah pemilik atas aset dan tentu saja berikut manfaatnya). Contohnya : Investor membeli mesin pabrik kemudian disewakan kepada pemesan (Alimin, 2010).

Jenis sukuk ijarah kedua adalah Sukuk ijarah Manafi' al-A'yan al-Musta'jarah atau Certificates of ownership of usufructs of existing assets, yaitu sukuk ijarah yang melambangkan kepemilikan atas manfaat dari aset (bukan wujud aset). Contohnya : Investor menyewa pesawat terbang, kemudian disewakan lagi kepada maskapai penerbangan. Jenis sukuk yang ketiga adalah sukuk ijarah Milkiyah al-A'mal al-Mujarah atau Certificates of ownership of services of a specified supplier. Contoh : jasa cleaning service sebuah rumah sakit selama jangka waktu tertentu, pelayanan perbaikan system pendingin ruangan dan lift, perusahaan penerbangan, kapal laut, computer, penyulingan minyak.

Skema pelaksanaan sukuk ijarah Milkiyah al-A'yan al-Mu'jarah adalah sebagai berikut :

(1) perusahaan (originator) memerlukan dana tunai, kemudian membuat kontrak sukuk ijarah dengan SPV; 
ljtihad: Jurnal Wacana Hukum Islam dan Kemanusiaan, Volume 18, No. 2, Desember 2018: 175-192

(2) kemudian wali amanat sebagai mediator antara originator dengan investor yang disebut Special Purpose Vibicle disingkat SPV menyerahkan sukuk ijarah kepada investor, investor membayar tunai;

(3) selanjutnya SPV membeli property (tanah dan bangunan) milik perusahaan untuk disewakan kembali kepada perusahaan selama 5 tahun;

(4) selama masa sewa perusahaan membayar uang sewa kepada investor melalui SPV setiap enam bulan sekali;

(5) pada saat jatuh tempo perusahaan membeli kembali property (aset ijarah) dari SPV;

(6) akhirnya SPV menyerahkan hasil penjualan property (aset ijarah) kepada investor.

Dari ketiga akad tersebut dikenal juga Sukuk Al Intifa'a hampir mirip dengan akad Sukuk Ijarah, dimana terdapat aset pendukung yang mendasari diterbitkannya sukuk tersebut. Underlying Asset yang dimaksud disini tidaklah berbentuk aktiva berwujud, melainkan dalam bentuk manfaat atas aset tersebut. Al Intifa'a yang dimaksud memiliki arti —mengambil manfaat, yaitu manfaat dari aset yang dijadikan sebagai Underlying Asset pada penjualan sukuk. Jadi investor atau pemegang sukuk memiliki hak atas penggunaan manfaat aset penerbit sukuk, namun tidak memiliki hak untuk memiliki aset tersebut. Dalam konteks pembahasan ini, underlying asset yang akan digunakan berasal dari aset wakaf (Syairozi, 2016: 387). Sukuk Al Intifa'a tersebut hampir selaras dengan skema pelaksanaan sukuk ijarah Manafi' al-A'yan al-Mustajarah atau Certificates of ownership of usufructs of existing assets (AAOIFI), yaitu sukuk ijarah yang melambangkan kepemilikan atas manfaat dari aset (bukan wujud aset), yaitu dengan skema sebagai berikut :

(1) Nadzir atau pengelola asset wakaf memerlukan dana tunai, kemudian membuat kontrak sukuk ijarah dengan SPV yang sebelumnya dilakukan pendataan bekerjasama dengan pihak BWI, Kemenkeu, BUMN, dan BI;

(2)kemudian wali amanat sebagai mediator antara Nadzir dengan investor yang disebut Special Purpose Vibicle disingkat SPV menyerahkan sukuk ijarah kepada investor, investor membayar tunai;

(3) selanjutnya SPV membiayai pengembangan asset wakaf tersebut (underlying asset) untuk dibangun fasilitas public baik sekolah, rumah sakit, hotel atau bentuk lain yang memberikan manfaat untuk semua pihak dan memberikan manfaat materil selama masa 
Analisis hukum Islam terhadap pengembangan wakaf berbasis sukuk...(Siska Lis Sulistiani, dkk.)

pengembangan dan sewa perusahaan dalam hal ini pengembang (BUMN) membayar uang sewa kepada investor dan sebagian kepada nadzir melalui SPV;

(4) pada saat jatuh tempo asset wakaf tersebut kembali pada nadzir secara pengelolaan dibantu oleh lembaga terkait melalui SPV.

\section{Kedudukan hukum pemberdayaan tanah tidak produktif melalui wakaf berbasis sukuk}

Sukuk berbasis wakaf merupakan sebuah inovasi dalam memberdayakan banyaknya asset wakaf yang tidak produktif di Indonesia. Karena pada hakikatnya wakaf seharusnya terus berkembang dan menghasilkan manfaat tanpa mengurangi inti dari asset awal wakaf. Wakaf berbasis sukuk berdiri dari 2 akad yang berbeda yaitu: pertama, wakaf. Wakaf yang dibangun atas akad tabarru atau akad yang bersifat sosial, tidak adanya imbal hasil yang bersifat materi yang diharapkan untuk wakif melainkan mengharapkan semata-mata ridha Allah SWT dan kemaslahatan hasil wakaf untuk umat yang dikelola melalui nadzir. Kedua, sukuk. Sukuk yang dibangun diatas akad tijaroh yang memiliki sifat bisnis. Dari kedua tujuan akad yang berbeda dari wakaf berbasis sukuk dikolaborasikan demi nilai maslahat yang lebih besar.

Bentuk akad wakaf yang digabungkan dengan sukuk ini akan tergantung dengan asset wakaf tersebut, agar tidak keluar dari tujuan utama dari wakaf itu sendiri. Salah satu upaya pendanaan dalam pengembangan wakaf ini yaitu melalui sukuk yang akan mendapatkan pendanaan melalui adanya dana tunai dari investor melalui SPV . Terkait aspek hukum yang pernah disinggung oleh Erwandi terkait bentuk akad yang digunakan dalam akad sukuk ijarah yang diserupakan dengan bai al-wafa dimana ada prasyarat dalam penjualan sebuah objek jual dalam akad jual beli, hal tersebut diharamkan oleh mayoritas para ulama dari madzhab maliki, syafii, hanbali dan sebagaian ulama madzhab Hanafi. pendapat mayoritas ulama klasik selarasn dengan Keputusan OKI pada tahun 1992 No.66 (4/7) (Erwandi, 2016). Yang menjadi catatan adalah bahwa kepemilikan underlying asset di tangan kepemilikan pemegang sukuk harusah kepemilikan yang hakiki dan dapat dikuasai penuh dan kepemilikan tersebut terus berlangsung hingga berakhirnya akad Sukuk (Erwandi, 2016). Ataupun, untuk menghindari kasus jual beli fiktif menurut OKI memutuskan pada akhir priode sewa asset sukuk dibeli dengan nilai pasar atau dengan nilai nominal, akan tetapi harus dibeli dengan nilai pasar atau dengan kesepakatan yang dibuat oleh kedua belah pihak pada saat itu. 
Adapun bai al-wafa menurut sebagaian madzhab hanafi diperbolehkan. Hal tersebut selaras dengan Kompilasi Hukum Ekonomi Syariah Pasal 112-115 yang memasukan bai al-wafa ini sebagai salah satu bentuk akad jual beli. Pasal 112 KHES bahwa jual-beli yang bergantung pada hak penebusan, penjual dapat mengembalikan uang seharga barang yang dijual dan menuntut barangnya dikembalikan dan pembeli sebagaimana pada ayat (1) berkewajiban mengembalikan barang dan menuntut uangnya kembali seharga barang itu. Adapund alam Pasal 113 KHES barang dalam jual-beli yang bergantung pada hak penebusan, tidak boleh dijual kepada pihak lain, baik oleh penjual maupun oleh pembeli, kecuali ada kesepakatan di antara para pihak.

Hal ini bercermin dari keberhasilan Bahrain yang pada tahun 1999 dewan syariah Bahrain memfatwakan boleh negaranya menerbitkan sukuk ijarah untuk membiayai belanja Negara. Dengan diterbitkannya sukuk ijarah tersebut Bahrain dapat mengumpulkan dana sebanyak 10 Milyar US Dollar. Keberhasilan tersebut memicu negara lain seperti Kuwait, Dubai, Malaysia dan Indonesia untuk mengikuti jejaknya.

Selain itu berdasarkan fatwa DSN MUI No. 95/DSN-MUI/VI/2014 tentang SBSN Ijarah Asset to be leased yang menjadi salah satu dasar fatwa terkait sukuk ijarah. Sukuk $\mathrm{Al}$ Intifa'a tersebut hampir selaras dengan skema pelaksanaan sukuk ijarah Manafi' al-A'yan al-Mustajarah atau Certificates of ownership of usufructs of existing assets (AAOIFI), yaitu sukuk ijarah yang melambangkan kepemilikan atas manfaat dari aset (bukan wujud aset). Salah satu Hadis Nabi riwayat Tirmizi dari 'Amr bin 'Auf hadis yang memperbolehkan:

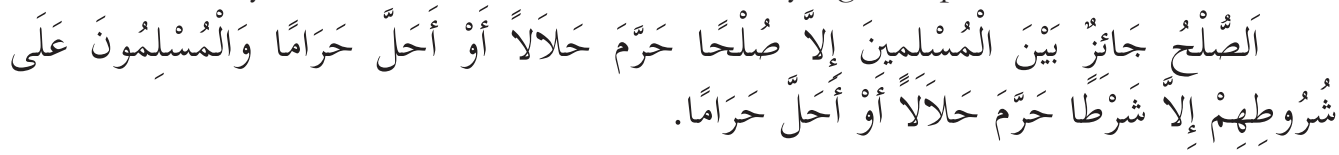

"Perdamaian dapat dilakukan di antara kaum muslimin kecuali perdamaian yang mengharamkan yang halal atau menghalalkan yang haram; dan kaum muslimin terikat dengan syarat-syarat mereka kecuali syarat yang mengharamkan yang halal atau menghalalkan yang haram."

Selain itu dalam Kaidah Fikih:

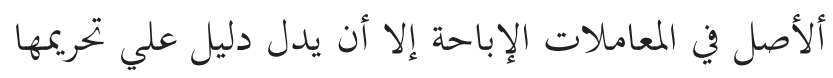

"Pada dasarnya, semua bentuk muamalah boleh dilakukan kecuali ada dalil yang mengharamkannya." 
Selain itu, dalam menetapkan fatwanya DSN MUI mengingat tentang bolehnya peran pemerintah melalui lembaga berwenang menetapkan fatwa yang terkait kemaslahatan wilayahnya.

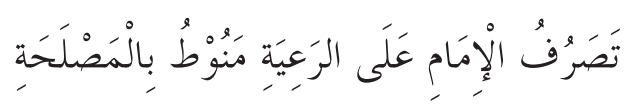

"Suatu tindakan (peraturan) pemerintah, berintikan terjaminnya kepentingan dan kemaslabatan rakyatnya ( Rofiq, 1998).

Akan tetapi masih ada beberapa aspek yang perlu diperhatikan dan harus disempurnakan dalam pengembangan instrument wakaf berbasis wakaf ini yaitu sebagai berikut: pertama, peraturan yang jelas dan khusus mengatur tentang sukuk wakaf. Diharapkan segera ada peraturan jelas tentang sukuk wakaf yang mengakomodasi wakaf dengan sukuk. Peraturan itu setidaknya membahas penggunaan dana wakaf uang untuk membeli sukuk agar mendapatkan return, hingga memungkinkan investor untuk mewakafkan sukuk yang dimilikinya. Membahas tentang pengelolaan wakaf, jangka waktu jatuh tempo investor sukuk wakaf apabila ada wanprestasi dan ketentuan-ketentuan lain yang dibutuhkan. Peraturan ini menjadi perlindungan hukum yang lebih jelas dan spesifik tentang pihak-pihak yang berkepentingan dalam sukuk wakaf ini.

Kedua, sertifikasi tanah wakaf yang masih menjadi masalah dalam bidang administratif. Bagi tanah wakaf yang belum bersertifikat wakaf yang merupakan sumbangan harta dari masyarakat untuk kepentingan umum dan juga kesejahteraan umum mestinya didukung penuh oleh pemerintah, baik dalam hal regulasi maupun sertifikasi. Sebenarnya sertifikasi tanah wakaf yang belum bersertifikat sudah diusahakan oleh Badan Wakaf Indonesia, namun ada beberapa yang tersendat. Selain itu, masih banyak juga para pengelola wakaf yang masih belum memiliki sertifikat kepemilikan tanah karena berbagai kendala administrative lainnya. Keterlibatan pemerintah seperti Otoritas Jasa Keuangan (OJK), Bank Indonesia (BI), Badan Pertanahan Nasional (BPN), dan BWI diperlukan dalam sertifikasi tanah wakaf yang berkendala dan menumbuhkan kesadaran untuk memiliki sertifikat tersebut kepada para pengelola wakaf.

Ketiga, membuat landasan syariah tentang penerbitan sukuk wakaf. Menurut Respati (2016), penerbitan sukuk dapat menggunakan aset wakaf sebagai underlying-nya selama memenuhi beberapa prinsip; Pertama, sepanjang pengelolaannya bisa untuk mempertahankan keawetan harta wakaf itu. Kedua, selama penerbitan sukuk akan memberi manfaat baik bagi 
ljtihad: Jurnal Wacana Hukum Islam dan Kemanusiaan, Volume 18, No. 2, Desember 2018: 175-192

kepentingan publik. Ketiga, selama tidak akan memberikan keuntungan tertentu kepada orang atau pihak tertentu.

\section{Penutup}

Mekanisme wakaf berbasis sukuk untuk pembedayaan tanah tidak produktif di Indonesia belum ada regulasi yang mendasarkan bentuk akad yang akan digunakan. Akan tetapi dari beberapa sumber yang telah disebutkan bahwa wakaf berbasis sukuk ini akan serupa dengan akad sukuk ijarah yang sedikit berbeda dalam bentuk investor atau pemegang sukuk hanya memiliki hak atas penggunaan manfaat aset penerbit sukuk, namun tidak memiliki hak untuk memiliki aset tersebut. Dalam konteks pembahasan ini, underlying asset yang akan digunakan berasal dari aset wakaf . Sukuk Al Intifa'a tersebut hampir selaras dengan skema pelaksanaan sukuk ijarah Manafi' al-A'yan al-Mustajarah atau Certificates of ownership of usufructs of existing assets, yaitu sukuk ijarah yang melambangkan kepemilikan atas manfaat dari aset (bukan wujud aset).

Analisis mekanisme dan kedudukan hukum wakaf berbasis sukuk ini yaitu bahwa wakaf dan sukuk berdiri dari 2 tujuan akad yang berbeda yaitu akad tabarru dan tijaroh, yang digabungkan dalam rangka menghadirkan nilai maslahat yang lebih besar. Kedudukan hukum wakaf berbasis sukuk ini jika dibangun diatas akad sukuk ijarah yang hampir serupa bai alwafa menurut jumhur ulama diharamkan, kecuali madzhab hanafi yang membolehkannya. Hal ini yang selaras dengan fatwa DSN MUI No. tentang dan Pasal 112-115 KHES tentang bai al-wafa. Terlepas dari perbedaan pendapat dalam konteks fiqh ini, perlu diperhatikan aspek regulasi yang jelas yang melandasi wakaf berbasis sukuk ini, memperhatikan perapihan administrasi asset wakaf baik sertifikat tanah dan bangunan wakaf maupun sertifikat wakaf dan perlu diperhatikan aspek legalitas syariah agar tujuan utama wakaf untuk kemaslahatan umat tetap dapat tercapai tanpa mengurangii nilai ataupun wujud dari asset wakaf tersebut.

\section{Daftar pustaka}

Anik, Iin Emy Prastiwi. 'Perkembangan Instrumen Sukuk dalam Mendukung Pembangunan Infrasuktur”. Jurnal Ilmiah Ekonomi Islam Surakarta, Vol.3 No.3. 2017.

Anwar, Syamsul. Studi Hukum Islam Kontemporer, Jakarta: RM Books. 2007. 
Analisis hukum Islam terhadap pengembangan wakaf berbasis sukuk...(Siska Lis Sulistiani, dkk.)

Agustianto. Wakaf Uang dan Peningkatan Kesejahteraan Umat. Artikel Zona Ekonomi Islam. di publikasikan pada Agustus. 2010.

Alimin. Aplikasi pasar sukuk dalam perspektif syariah (studi analisis kesesuaian syariah terhadap aplikasi pasar sukuk domestic dan global). Disertasi doctor . Jakarta : Sekolah Pascasarjana UIN Syarif Hidayatullah. 2010.

Al-Usman, Syaikh Muhammad bin Shalih. Panduan Wakaf, Hibah, dan Wasiat Menurut alQur'an dan as-Sunnah. Jakarta:Pustaka Imam Syafi'I. 2008.

Baskan, Birol. Wagf System As A Redistribution Mechanism In Ottoman Empire. Chicago: Northwestern University Department of Political Science. 2002.

Bakar, Abu L., Nyulistyowati, Handayani, T., Sukmadilaga, Andri, F. "Sukuk sebagai Alternatif Pembiayaan Infrastruktur dalam rangka Perluasan dan Percepatan Pembangunan”. Universitas Padjadjaran. 2012.

Bakar, Abu L.,Handayani, T. "Kesiapan Infrastruktur Hukum Dalam Penerbitan Sukuk (Surat Berharga Syariah) Sebagai Instrumen Pembiayaan Dan Investasi Untuk Mendorong Pertumbuhan Pasar Modal Syariah Indonesia”. Jurnal Jurisprudence Vol.7 N0.1 Juni. 2017.

Budiman, Achmad Arief . "Akuntabilitas Lembaga Pengelola Wakaf “. Jurnal Walisongo UIN Walisongo Semarang Volume 19, Nomor 1, Mei 2011.

Datuk, B. "Sukuk Dimensi Baru Pembiayaan Pemerintah untuk Pertumbuhan Ekonomi”. Jurnal Riset Akuntansi dan Bisnis, Vol.4. No.1. Fakultas Ekonomi Universitas Sumatra Utara. 2014.

Direktorat Pemberdayaan Wakaf. Model Pengembangan Wakaf Produktif. Jakarta: Direktorat Pemberdayaan Wakaf. 2008.

Furqon, Ahmad. "Model-Model Pembiayaan Wakaf Tanah Produktif”. Jurnal Economica Jurnal Ekonomi Islam Vol.V Edisi.1 Mei. Semarang: UIN Walisongo. 2014.

Ghofur, Abdul. Hukum dan Praktik Perwakafan di Indonesia. Yogyakarta : Pilar Media. 2006.

Hay'ah Muhasibah Wal Muraja'ah Lilmu'assasaah Al-Maaliyah Al-Islamiyyah. Al-Ma'ayir asy-Syar'iyyah. AAOIFI. 2017.

Haiyazid, Mohd, dkk. Pembangunan Tanah Wakaf Melalui Hotel Wakaf (Strategi Lautan Biru Nasional). Kualalumpur: Universiti Sains Islam Malaysia. 2014.

Kemenkeu. Sukuk. Negara (instrument keuangan berbasis syariah). Jakarta: Kemenkeu. 2015.

Kemenkeu. Kumpulan Peraturan Surat Berharga Syariah Neagara (Pengaturan terkait Penerbitan dan Underlying Asset). Jakarta: Kemenkeu. 2017.

Kompilasi Hukum Ekonomi Syariah. Bandung: Fokus Media. 2008.

Masyitoh, Siti, Syamsiyyah. T.th. Waqaf asham wa sukuq wal huquq ma'nawiyyah wal manaafi'. Uni Emirat Arab: Dauroh Tasi'ah 'Asyroh imaroh Asy-Syariqoh. 
ljtihad: Jurnal Wacana Hukum Islam dan Kemanusiaan, Volume 18, No. 2, Desember 2018: 175-192

Medias, Fahmi. "Wakaf Produktif”. Jurnal Lariba , Jurnal Ekonomi Islam, Vol. IV,No.1 Juli . Yogyakarta: UII. 2010.

Musari, Khairunnisa. "Waqf-Sukuk, Enhancing the Islamic Finance For Economic Sustainability in Higher Education Institutions". Papers World Islamic Countries University Leaders Summit (WICULS). 2016.

Muhamad, Nasrul Hisyam Nor, dkk. "Konsep Maqasid Syariah Dalam Pengurusan Wakaf". International Journal of Islamic Cibilizational Studies Umran . Johor: UTM. 2015.

Omar, Hasim Hydzulkifli, dkk. "The Application of Sukuk in Sustaining The Waqf Asset:Experience of Selected Waqf Trustee". Shariah journal, Vol.21, No.2. Kualalumpur: Universitas Malaya. 2013.

Otoritas Jasa Keuangan . Statistik Sukuk Mei 2017. http://www.ojk.go.id/id/kanal/syariah/ data-dan-statistik/data-produkobligasi syariah/Documents/Pages/StatistikSukuk---Mei 2017/Statistik\%20Sukuk\%20Mei\%202017.pdf . 2017.

Respati, Y. Ini Syarat Penerbitan Sukuk dengan Underlying Aset Wakaf. diakses pada tanggal 31 Juli 2017 pukul 18:33

Rivai, Veithzal dkk. Islamic Banking and Finance. Yogyakarta: BPFE. 2012.

Rofiq, Ahmad . Hukum Islam di Indonesia, Jakarta: PT.Grafindo Persada. 1998.

Sulistiani, Siska Lis. Pembaruan Hukum Wakaf di Indonesia. Bandung: Refika Aditama. 2017. . Hukum Perdata Islam di Indonesia. Jakarta: Sinar Grafika. 2018.

Somantri , Gumilar Rusliwa. "Memahami Metode Kualitatif". MAKARA, Jurnal Sosial Humaniora, Vol. 9, No. 2. Fakultas Ilmu Sosial dan Ilmu Politik, Universitas Indonesia: Depok. 2005.

Syairozi, M Imam, Septyan Budy Cahya dkk. "Sukuk AlIntifaa: Integrasi Sukuk dan Wakaf dalam meningkatkan produktifias Sektor Wakaf Pendorong Investasi Pada Pasar Modal Syariah”. Jurnal Penelitian Ilmu Manajemen Univ. Islam Lamongan Vol.II No.2 . 2016.

Tarmizi, Erwandi. Harta Haram Muamalat Kontemporer. Berkat Mulia Insani Publishing: Bogor. 2015.

Trisilo, Rudi Bambang. "Penerapan Akad Pada Obligasi Syariah dan Sukuk Negara (Surat Berharga Syariah Negara/SBSN)”. Economic: Jurnal Ekonomi dan Hukum Islam Vol.4 No.1. Banyuwangi: Sekolah Tinggi Agama Islam Banyuwangi. 2014.

Qohaf, Mundzir. Manajemen Wakaf Produktif. Jakarta: Khalifa. 2008

\section{Sumber online}

http://www.antaranews.com/berita/475244/menag-potensi-wakaf-sangat-besar 